\section{A Patient Activities of Daily Living Scale for Amyotrophic Lateral Sclerosis}

Laura Herbelin, CCRP ${ }^{1}$, Jeffrey Statland, MD ${ }^{1}$, Kim

Kimminau, $\mathrm{PhD}^{2}$, Lemuel R. Waitman, $\mathrm{PhD}^{3}$, Kelli

Johnsen $^{4}$, Sally Dwyer ${ }^{5}$, Andrew J Heim, CCRP ${ }^{1}$

Richard Barohn, $\mathrm{MD}^{6}$ and the Greater Plains

Collaborative ALS Study Group ${ }^{7}$

${ }^{1}$ Department of Neurology, University of Kansas

Medical Center, Kansas City, KS

${ }^{2}$ Department of Family Medicine and Community

Health, University of Kansas Medical Center, Kansas City, KS

${ }^{3}$ Department of Internal Medicine, University of Kansas Medical Center, Kansas City, KS

${ }^{4}$ Patient Advocate

${ }^{5}$ ALS Association Mid-America Chapter, Stakeholder Advocate

${ }^{6}$ University of Missouri, Columbia, MO

${ }^{7}$ See Appendix 2*

Keywords: Amyotrophic Lateral Sclerosis, ALS, Activities of Daily Living, ADL, Scale, Neuromuscular, Outcome measures, Patient Reported Outcome, Pragmatic research

\section{ABSTRACT}

Background: Motor neuron disorders are rare, progressive neurodegenerative diseases which affect multiple domains of motor function. The ability to assess function from home using an electronic medical record (EMR) would facilitate pragmatic studies.

Objective: To develop a Patient Activity of Daily Living scale for Amyotrophic Lateral Sclerosis and other motor neuron disorders (PADL-ALS) to support large pragmatic trials.

Methods: The Greater Plains Collaborative Clinical Data Research Network (GPC) developed and tested the feasibility of using the PADL-ALS. We convened patient and caregiver focus groups and in-person meetings to recommend changes to the ALS Functional Rating ScaleRevised (ALSFRS-R), which clarified language and added questions about pseudobulbar affect, pain, and faith. Feasibility was determined by conducting a survey of participants identified using EMR-computable phenotypes and returned via patient-preferred modalities.

Results: Surveys were distributed to 1079 participants at nine GPC health systems. The survey response rate was $44.4 \%$ (range $12.9-57.66 \%$ ): male to female ratio
1.56; $84 \%$ self-identified as a patient with ALS. Patient respondents used computers or tablets more frequently than caregivers responding on their behalf. The PADLALS correlated to clinic-performed ALSFRS-R within 4 weeks of survey completion ( $\mathrm{n}=33$, rho=0.93, Kansas only). The pseudobulbar affect question correlated to functional motor burden. Over $80 \%$ agreed to be contacted for future research opportunities.

Conclusion: We demonstrated the feasibility of determining functional burden with the PADL-ALS using an EMR-computable phenotype. Future directions include implementing the PADL-ALS to answer pragmatic questions about ALS care.

\section{Introduction}

Amyotrophic Lateral Sclerosis (ALS) is the most common progressive motor neuron disease with an estimated US prevalence of 1:20,000 or 16,000 affected individuals in the US.(1) It is characterized by loss of motor function, including strength, swallowing, speech and breathing.(2) Median survival is approximately 2 years with early death or slowly progressive with survival $>5$ years. (2) Other motor neuron diseases demonstrate variable progression and include: primary lateral sclerosis (PLS), a pure upper motor neuron variant, and progressive muscular atrophy (PMA), a pure lower motor neuron variant. The ability to gain real-world information on the effectiveness for medications for ALS is limited. This creates a standard of care gap, with unclear information about who will

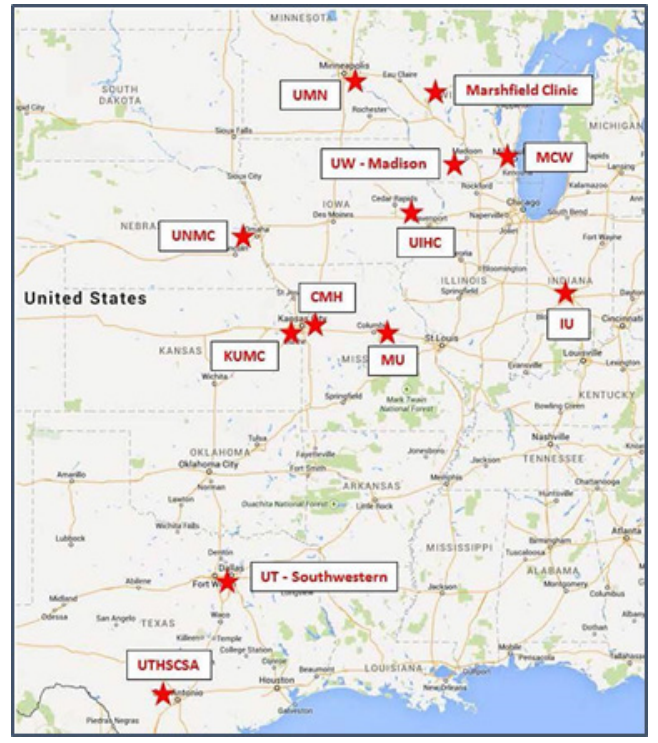

Figure 1. the GPC Network is comprised of 12 midwestern academic institutions with the EMR connected. Children's Mercy was excluded as ALS patients are not seen there. Indiana University and University of Missouri joined the network after the survey was completed. 
best benefit, and no information about utility for PLS or PMA. There is a validated patient reported functional measure used in clinical trials, the ALS Functional Rating Scale - Revised (ALSFRS-R) that was developed largely without patient input.(3,4) A patient-centric functional disease measure could improve existing disease altering or symptomatic therapies for motor neuron disorders.

The Greater Plains Collaborative (GPC) is a PCORIfunded Clinical Data Research Network (PCORnet) comprised of 12 midwestern health systems. (Figure 1).(5,6) The GPC used this opportunity to develop and test the feasibility of deploying a Patient Reported Activity of Daily Living Scale (PADL-ALS) for patients with motor neuron disease (ALS,PLS and PMA), created with patient input, and tested by identifying likely patients using EMRcomputable phenotypes, and multiple modalities for completion.

\section{Methods}

We used a multi-step process to create and test the feasibility of the PADL-ALS. We conducted virtual and in-person patient focus groups and meetings with key stakeholders during the development phase followed by a prospective de-identified patient survey in the feasibility phase conducted at nine US sites from 02/02/2015 through 01/10/2017. The survey study protocol was reviewed by the University of Kansas Medical Center Central IRB, and consent or assent was obtained from all survey participants.

PADL-ALS development. We convened a patient and caregiver focus group (5 patients, and 2 caregivers)

Table 1. Changes to the ALSFRS-R.

\begin{tabular}{|l|}
\hline Modify the instructions \\
\hline $\begin{array}{l}\text {-ALSFRS-R - 'We are comparing how you are today to before } \\
\text { the start of the disease' }\end{array}$ \\
\hline TO \\
\hline $\begin{array}{l}\text {-PADL-ALS - 'Please think about how your are doing on an } \\
\text { average day over the past month or so (and this includes your } \\
\text { routine use of therapies, devices, medications, etc.) when } \\
\text { answering these questions. Please choose only l answer. }\end{array}$ \\
\hline $\begin{array}{l}\text { Changed the wording/more information on some questions } \\
\text { with) }\end{array}$ \\
\hline $\begin{array}{l}\bullet \text { Added (can include zipper pulls, button fasteners, sitting } \\
\text { instead of standing) to the intermittent assistance or } \\
\text { substitute methods in Dressing } \& \text { Hygiene }\end{array}$ \\
\hline$\bullet$ Adjusting sheets instead of bedclothes \\
\hline \begin{tabular}{l} 
Discussed whether to complete online or paper \\
\hline$\bullet$ Most of the group wanted to complete online
\end{tabular} \\
\hline
\end{tabular}

via telephone; interviews were facilitated by the KUMC GPC community engagement officer; and she wrote a summative report. The facilitator and KUMC research team explained that the goal was to create afunctional outcome measure deemed valuable from both the clinician and patient/care giver perspectives to be used in future comparative effectiveness studies in ALS. During this first meeting, patients stated their desire for a simple method to communicate their health functional status and areas of concern to their health care providers. The ALSFRS-R is widely used in both ALS Association and Muscular Dystrophy Association multidisciplinary ALS care clinics, so patients and their caregivers were familiar with the ALSFRS-R. Participants in the focus group believed that the ALSFRS-R was a good starting point. They expressed interest in a form that they could fill out on their own, from home, preferably on a tablet, and send to their health care provider. They offered that it would be beneficial if they could complete the survey and provide a functional status update either prior to their next appointment, or to complete over time so that they could track their condition from home. They recommended several changes to the current ALSFRS-R. First, patients requested clarification and simplification of medical terminology in the existing ALSFRS-R. Patients suggested the addition of questions on pain and concerning bouts of laughter or crying (pseudobulbar affect). The focus group recommendations were incorporated into the existing ALSFRS-R, and two additional questions were added following the ALSFRS-R question template, where $4=$ unaffected, and $\mathrm{O}=$ severe impairment interfering with daily function (Table 1 and Figure 2).

Following the focus group, an in-person meeting was held at the annual GPC meeting in Kansas City, KS in August 2014, and included healthcare providers representing each GPC site, a group of patients and caregivers not previously

Figure 2. Additional questions.

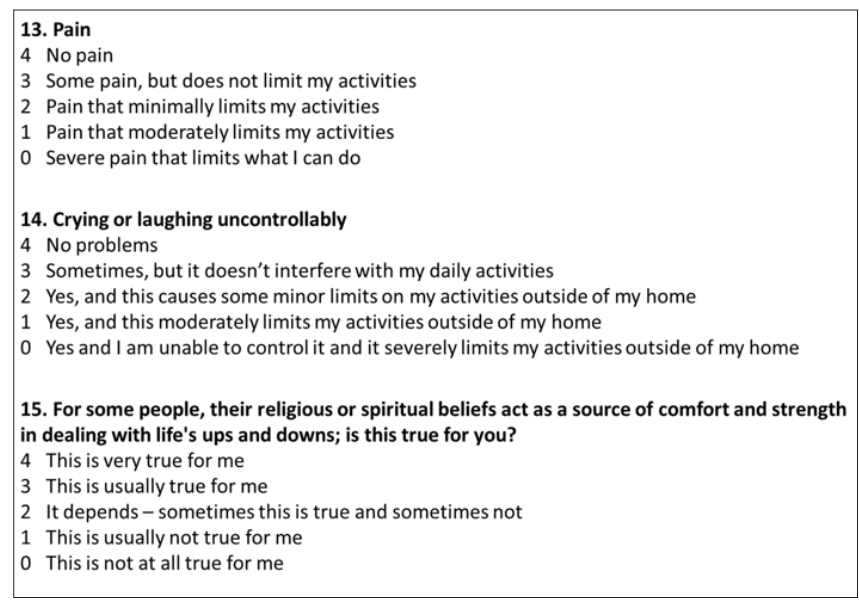


engaged in the study, and patient advocacy representatives. At that meeting, the revised version of the ALSFRS-R with additional questions was reviewed, and additional recommendations were made. The GPC meeting group endorsed the focus group recommended changes, and requested adding three additional domains of interest that include a non-denominational question regarding faith, questions about participating in future research, and possible future research directions to the survey. The final survey, now called the PADL-ALS to reflect the patient input in its design, also includes questions about demographics, about type of motor neuron disease, and disease characteristics (i.e. symptom onset, diagnosis, current medications). (Appendix 1)

PADL-ALS survey. Survey participants were identified using a multi-step process which included identification of patient lists using an EMR-computable phenotype; followed by local ALS study team review of patient lists. The EMR computable phenotype included the following searchable parameters: 1) motor neuron disease diagnostic codes (ICD9 codes: 335.20, 335.29, and 335.24), 2) living, 3) >1 encounter with the motor neuron disease diagnostic code; and 4) seen within the last 2 years. Motor neuron disorders have the benefit of specific ICD9 or ICD10 codes, and the fact virtually all patients are followed in multi-disciplinary clinics due to the nature of the disease. A search of the nine connected EMRs was performed using i2b2 queries. $(7,8)$ Each site received an electronic list with the names and address of the patients that met those criteria which could be edited using a REDCap(9) database. The initial number per site identified using the EMR-computable phenotype, and the number retained after local review is presented in Table 2. The survey was distributed using a variety of techniques depending on site capabilities which included: invitation letters sent through EMR patient portals; invitations sent via the US postal service mail; and in-person recruitment during ALS clinic visits. Six weeks after the initial survey distribution, individuals who had not responded were contacted with a second invitation, and 2 weeks later with a phone call by their care site.

Statistical considerations. A goal of the GPC network survey was to provide proof of concept that the network can accurately identify and recruit patients; therefore, response rate to the survey was the primary study outcome. The PCORI defined goal for survey response was $50 \%$. Response rate was determined as: $100 \mathrm{X}$ (Number replied either yes or no to complete the survey) / (Number sent Number deceased or "other"). "Other” included participants who could not be contacted (moved, disconnected phone, etc). Descriptive statistics were used to describe the overall ALS clinic cohort including demographics (age, sex, race, ethnicity, living situation, occupation, years of education) and functional burden as identified by survey response (clinical diagnosis, and functional status). Responders as a group (GPC overall) and by participating site were compared to published regional and national ALS demographics to identify any differences in GPC responder characteristics. (1) The PADL-ALS questions 1-12 overlap by content to the ALSFRS-R, so were used to assess functional burden. Comparison between the PADL-ALS Q1-12 and in-person clinic performed ALSFRS-R between research staff at the University of Kansas Medical Center ALS clinic and patient within 4 weeks of survey response was done using Spearman correlation. All statistical testing was two-sided, and 0.05 was the cut off for level of significance. Analysis was performed using SAS 9.3 (Greensboro, NC).

\section{Results}

The initial EMR-computable phenotype identified 1800 possible motor neuron disease participants seen in the last 2 years across the GPC network of sites (Table 2).

After review by local ALS clinic site personnel, 1079 were determined to be active motor neuron participants seen in clinic, or $61 \%$ (range 19-100\%). The total number sent out was then adjusted based on whether the participant was still living, and maintained an active contact information in the EMR to 972 (or 90.1\%). The response rate for the survey was $44.4 \%$ overall, and varied by site (19-58\%, Table 3).

The majority of participants self-identified as ALS (83\%), and the median age of responders was 66.5 years (25\% quartile [Q1] 53, 75\% quartile [Q3] 73, Table 3). When comparing survey respondents to demographics in the CDC ALS registry, our respondents were on average older, and more frequently non-Hispanic white. The median symptom duration was consistent with other large

Table 2. Number of participants identified using the EMR computable phenotype, and the \% retained after local ALS clinic staff review.

\begin{tabular}{|l|l|l|l|}
\hline \multicolumn{1}{|c|}{ Site } & \# identified & $\begin{array}{c}\text { \% retained after site } \\
\text { review }\end{array}$ & $\begin{array}{c}\text { \# sent } \\
\text { out }\end{array}$ \\
\hline KUMC & 361 & 72 & 260 \\
\hline Iowa & 88 & 82 & 72 \\
\hline MCW & 163 & 100 & 163 \\
\hline UMN & 237 & 24 & 57 \\
\hline UTHSCSA & 267 & 63 & 168 \\
\hline UNMC & 78 & 89 & 69 \\
\hline UTSWMC & 271 & 80 & 217 \\
\hline Marshfield & 89 & 29 & 26 \\
\hline Wisconsin & 246 & 19 & 47 \\
\hline Total & 1800 & 62 & 1079 \\
\hline
\end{tabular}


Table 3. Response rate by site.

\begin{tabular}{|c|c|c|c|c|c|c|c|c|}
\hline Site & Num & Numerator ${ }^{*}$ & Completed & Refused & Denominator $^{*}$ & Deceased & Other & Response Rate (\%) \\
\hline KUMC & 265 & 128 & 106 & 22 & 222 & 22 & 21 & 57.66 \\
\hline Iowa & 72 & 8 & 6 & 2 & 62 & 7 & 3 & 12.90 \\
\hline MCW & 163 & 87 & 74 & 13 & 153 & 10 & 0 & 56.86 \\
\hline UMN & 58 & 26 & 26 & - & 58 & - & - & 44.83 \\
\hline UNMC & 69 & 35 & 32 & 3 & 69 & 0 & 0 & 50.72 \\
\hline UTHSCSA & 167 & 73 & 71 & 2 & 132 & 3 & 32 & 55.30 \\
\hline UTSWMC & 213 & 58 & 51 & 7 & 210 & 3 & 0 & 27.62 \\
\hline Marshfield & 26 & 9 & 8 & 1 & 24 & 1 & 1 & 37.50 \\
\hline Wisconsin & 46 & 8 & 8 & - & 42 & 4 & - & 19.05 \\
\hline TOTAL & 1079 & 432 & 382 & 50 & 972 & 50 & 57 & 44.44 \\
\hline
\end{tabular}

${ }^{*}$ Response rate $=$ numerator $($ number responded + number refused) $/$ denominator $($ number sent $-[$ deceased + other $])$. KUMC $=$ Kansas University Medical Center; MCW = Medical College of Num = number; Wisconsin; UMN = University of Minnesota; UNMC $=$ University of Nebraska Medical Center; UTHSCSA = University of Texas Health Center - San Antonio; UTSWMC $=$ University of Texas Southwestern Medical Center.

motor neuron disease cohorts, with ALS around 2 years, and PLS 8 years. Figure 4 shows how the questionnaire was completed, and the method used: $68.3 \%$ of surveys were completed by patients who typically used a computer or tablet more frequently (49\% of the time) compared to surveys completed by caregivers on behalf of the patients, who preferred paper (64\% of the time, Figure 3 ).

Evaluating the PADL-ALS questions that correspond to the ALSFRS-R (PADL-ALS Q1-12, Table 4) one can see a breakdown of functional burden that matches the motor neuron disease subtype, with ALS most severely affected (PADL-ALS Q1-12 median 29) and with a broader range (Q1, Q3 21, 38), than PLS or PMA. For a subgroup of respondents at the University of Kansas Medical Center we compared the PADL-ALS Q1-12 to in-person clinic evaluator assessed ALSFRS-R obtained within 4 weeks of the survey response date: and the PADL-ALS and ALSFRS-R questions were correlated ( $\mathrm{n}=33$, Spearman's rho $=0.93$, Figure 4).

Pain did not show any correlation to the PADL-ALS Q1-12, even though $>50 \%$ of respondents reported pain, and $23.8 \%$ reported pain impacting their daily life (Table 5).

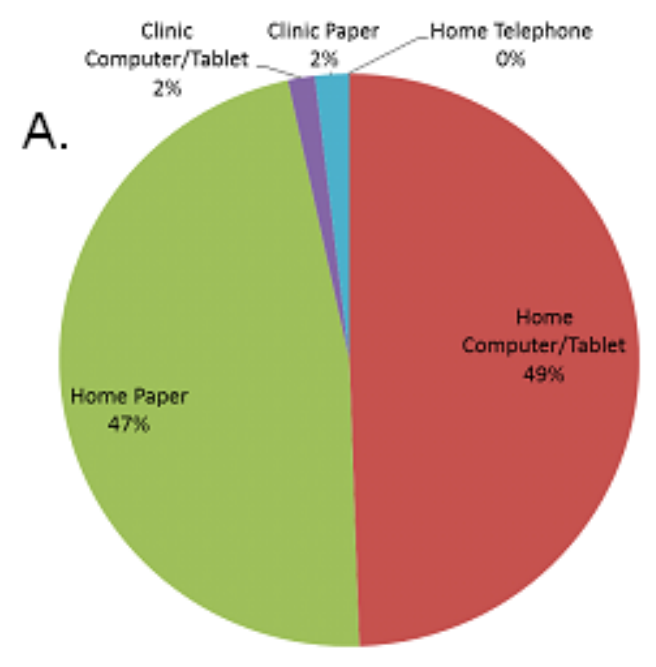

Patient $\mathrm{n}=261$

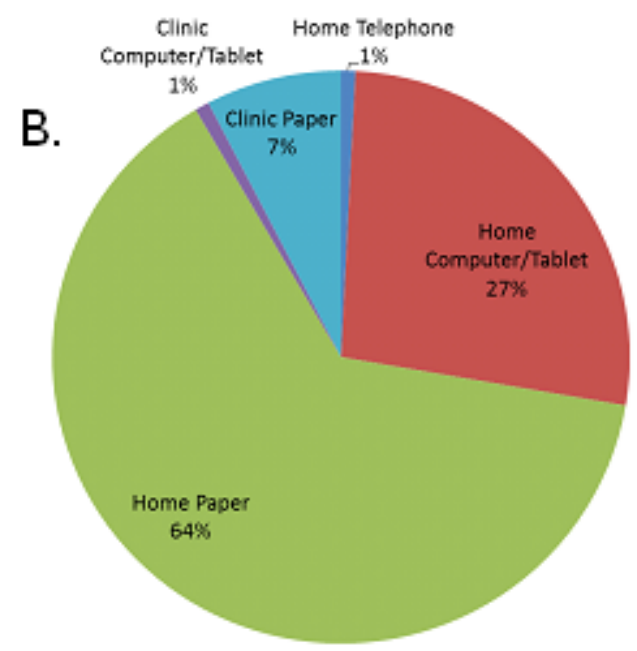

Patient via Caregiver $n=122$

Figure 3. Preferred modality for completing survey for patient completed surveys (A), and for surveys completed with the assistance of a caregiver (B). Patients were more likely to use a home computer or tablet. 
Table 3. Survey respondent characteristics.

\begin{tabular}{|c|c|c|c|c|c|c|}
\hline & $\overline{A L S}$ & PLS & PMA & Other & Total & CDC ALS Registry \\
\hline $\mathbf{n}$ & 317 & 40 & 7 & 18 & 382 & 12187 \\
\hline M:F & 1.6 & 1.5 & 1.3 & 0.9 & 1.5 & 1.45 \\
\hline \multicolumn{7}{|c|}{ Age (\%) } \\
\hline 18-39 & $6(1.9)$ & $0(0.0)$ & $0(0.0)$ & $0(0.0)$ & $6(1.6)$ & $186(9.7)$ \\
\hline $40-49$ & $22(6.9)$ & $\mathrm{l}(2.5)$ & $0(0.0)$ & $0(0.0)$ & $23(6.0)$ & $396(20.6)$ \\
\hline $50-59$ & $66(20.8)$ & $9(22.5)$ & $0(0.0)$ & $4(22.2)$ & $79(20.7)$ & $616(32.0)$ \\
\hline $60-69$ & 109 & $13(32.5)$ & $3(42.9)$ & $1(5.6)$ & $126(33.0)$ & $457(23.7)$ \\
\hline $70-79$ & $94(29.7)$ & $13(32.5)$ & $3(42.9)$ & $8(44.4)$ & $118(30.9)$ & $152(7.9)$ \\
\hline$>80$ & $20(6.3)$ & $4(10.0)$ & $1(14.3)$ & $3(16.7)$ & $28(7.3)$ & $27(1.4)$ \\
\hline Median Sx Dur (Q1, Q3) & $2(1,5)$ & $8(5,13)$ & $4(0,6)$ & $3(1,15)$ & $3(1,6)$ & - \\
\hline $\begin{array}{l}\text { Median PADL-ALS Q1- } \\
12(\mathrm{Q1}, \mathrm{Q} 3)\end{array}$ & $\begin{array}{l}29(21, \\
38)\end{array}$ & $\begin{array}{l}37(30, \\
40)\end{array}$ & $27(25,35)$ & $\begin{array}{l}35(27, \\
39)\end{array}$ & $30(22,38)$ & \\
\hline \multicolumn{7}{|c|}{ Race (\%) } \\
\hline White & $\begin{array}{l}284 \\
(89.6)\end{array}$ & $32(80.0)$ & $6(85.7)$ & $16(88.9)$ & $338(88.5)$ & $9638(79.1)$ \\
\hline Black & $7(2.2)$ & $3(7.5)$ & $0(0.0)$ & $0(0.0)$ & $10(2.6)$ & $798(6.5)$ \\
\hline Other & $6(1.9)$ & $2(5.0)$ & $0(0.0)$ & $0(0.0)$ & $8(2.1)$ & $535(4.4)$ \\
\hline Unknown & $20(6.3)$ & $3(7.5)$ & $1(14.3)$ & $2(11.1)$ & $26(6.8)$ & $1216(10.0)$ \\
\hline
\end{tabular}

ALS = amyotrophic lateral sclerosis; PLS = primary lateral sclerosis; PMA = progressive muscular atrophy; CDC = Center for Diseases Control; $\mathrm{n}=$ number; $\mathrm{M}$ = male; $\mathrm{F}$ = female; $\mathrm{Sx}=$ symptom; Dur = duration;

Fewer patients reported crying or laughing uncontrollably, but this symptom showed a moderate correlation to the PADL-ALS Q1-12 (Spearman's rho=0.35, $\mathrm{p}<0.001$ ). For the non-denominational question about faith, over $50 \%$ of respondents indicated that religion or spiritual beliefs act as a source of comfort, however responses were not correlated to functional burden as measured in the PADL-ALS Q1-12.

Survey respondents were asked how interested they would be in participating in future research, and eight in ten (82\%) indicated interest in hearing about future research. To prepare for possible pragmatic studies in ALS, we asked what direction they would like to see research take beyond the testing of investigational drugs. The highest percentage of respondents indicated interest in studies that address diet $(49.2 \%)$ or use of vitamins or supplements $(61.8 \%$, Supplemental table e-2).

\section{Discussion}

We used a multi-step process to develop a patientoriented activity of daily living scale for pragmatic studies in ALS. We developed a survey to demonstrate the feasibility of using EMR-computable phenotypes to identify patients, and ease of using those identified to conduct a survey on patient-preferred content and response modalities. After review, $61 \%$ of the EMR-computable phenotype identified candidates were confirmed as ALS patients and considered appropriate to receive the survey. The survey response rate was $44 \%$, just below the PCORI-identified target, but ranged from 19-58\% among the nine sites involved in the study. Patient respondents were more likely to use and prefer electronic response format. This study shows that

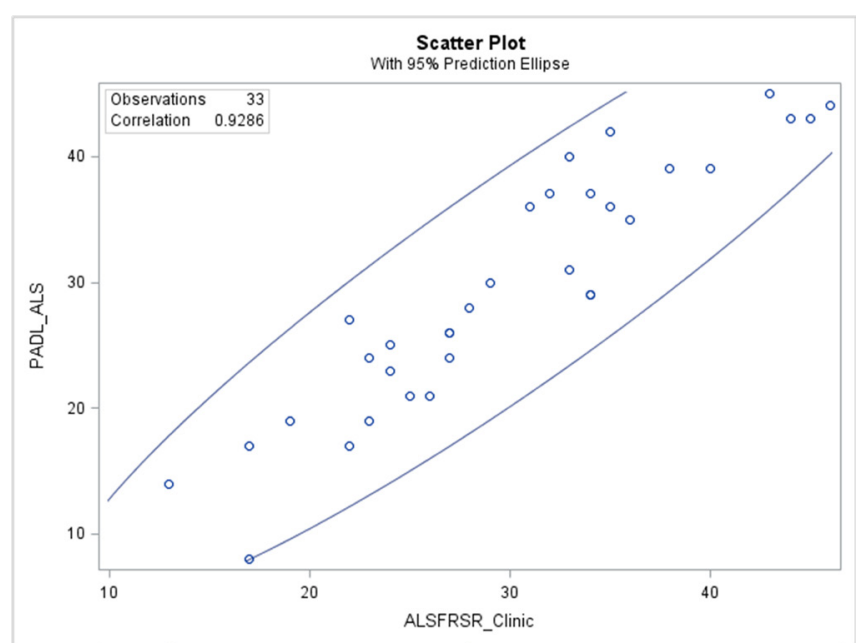

Supplemental Figure e-2. Relationship of PADL-ALS Q112 to clinic performed ALSFRS-R. 
Table 5: Additional symptom and research questions.

\begin{tabular}{|c|c|}
\hline Question & Erea $(\%)$ \\
\hline \multicolumn{2}{|l|}{ Pain } \\
\hline No pain & $166(43.8 \%)$ \\
\hline Some pain, but does not limit my activities & $123(32.5 \%)$ \\
\hline Pain that minimally limits my activities & $45(11.9 \%)$ \\
\hline Pain that moderately limits my activities & $33(8.7 \%)$ \\
\hline Severe pain that limits what I can do & $12(3.2 \%)$ \\
\hline \multicolumn{2}{|l|}{ Crying or laughing uncontrollably } \\
\hline No problems & $242(63.9 \%)$ \\
\hline Sometimes, but it doesn't interfere with my daily activities & $107(28.2 \%)$ \\
\hline Yes, and this causes some minor limits on my activities outside of my home & $20(5.3 \%)$ \\
\hline Yes, and this moderately limits my activities outside of my home & $8(2.1 \%)$ \\
\hline Yes and I am unable to control it and it severely limits my activities outside of my home & $2(0.5 \%)$ \\
\hline \multicolumn{2}{|l|}{$\begin{array}{l}\text { For some people, their religious or spiritual beliefs act as a source of comfort or strength in } \\
\text { dealing with life's ups and downs; is this true for you? }\end{array}$} \\
\hline This is very true for me & $172(45.3 \%)$ \\
\hline This is usually true for me & $76(20 \%)$ \\
\hline It depends - sometimes this is true and sometimes not & $63(16.6 \%)$ \\
\hline This is usually not true for me & $31(8.2 \%)$ \\
\hline This is not at all true for me & $38(10 \%)$ \\
\hline \multicolumn{2}{|l|}{$\begin{array}{l}\text { Would you be willing to be contacted about opportunities to take part in our ALS Specialty } \\
\text { Clinics medical research? }\end{array}$} \\
\hline Yes! Please count me in! & $192(51.4 \%)$ \\
\hline Please ask me about a specific research project, and then I'll decide & $114(30.6 \%)$ \\
\hline No, I'm not able to at this time & $67(18 \%)$ \\
\hline $\begin{array}{l}\text { In addition to brand new experimental treatments for ALS, it is also important that we study } \\
\text { how to best use currently available treatments. Which of the following clinical research } \\
\text { questions would you be interested in knowing the answer to? (check all that apply) }\end{array}$ & \\
\hline Is there a benefit to combining drug therapies in ALS? & $170(40.5 \%)$ \\
\hline Are there vitamin combinations/herbal supplements which can slow down ALS? & $236(61.8 \%)$ \\
\hline Does starting BiPAP earlier provide any benefit in ALS? & $101(26.4 \%)$ \\
\hline Do special diets have any role in treatment of ALS? & $188(49.2 \%)$ \\
\hline What is the best way to treat throat spasms that lead to choking or coughing? & $129(33.8 \%)$ \\
\hline
\end{tabular}


using a computable phenotype and remote or "low touch" strategies to recruit survey participants with ALS can yield substantial engagement. Furthermore, respondents shared enthusiasm for being contacted about future research opportunities (82\%).

This was the first attempt to utilize the Greater Plains Collaborative network of connected EMRs to and REDCap to store data, and to try to utilize this network to identify and carry out an ALS research study. $(8,9)$ The EMR identified 1800 potential subjects that met the criteria for the survey, and 1079 individuals were deemed eligible to receive a survey (range $19-100 \%$ ). There are many considerations when using an EMR-computable phenotype for recruitment in ALS studies. While lists can be filtered using Social Security death index,(10) there will still be individuals who may be deceased on the captured lists. Patients need to have up-to-date contact information or they cannot be contacted effectively. Different EMRs may have different mechanisms for tying encounters to diagnosis codes, and individual clinics may have different customs for using the diagnosis codes for ALS and related disorders. This variability introduces challenges to making sure all eligible individuals who meet the computable phenotype are recognized. While the broad implementation of EMRs was supposed to reduce the rate of misdiagnosis in medical records, this remains an important problem especially when electronically approaching patients regarding a terminal illness such as ALS.(11) Some of the names on the computable phenotype list were not known to the physician and since this disease usually requires specialized care, the physician did not feel comfortable sending out the survey to unknown individuals. Furthermore, the physician and/ or nurse may make the decision to not involve the patient if they believe that the patient is too ill or that it would be too difficult for the patients to respond. Despite these reservations, EMR-developed lists have a real possibility to mechanize and simplify the recruitment process, as additional search terms could be added, including age, gender, lab values, etc. to further refine the resulting registry.

The study participant population was older than comparable demographics from the CDC ALS registry. (1) This likely reflects issues related to our Midwestern locations, and a type of survival bias in clinic, where approximately $50 \%$ or patients will be dying within 2 years, leaving older survivors over-represented in clinics. Additional issues related to EMR data is similar to issues when evaluating registries: data is limited to what is collected at the time of the clinical visits; data quality suffers from incomplete or missing data; and there may be referral bias regarding who is referred to the academic medical centers. (12) Our population was more racially homogeneous than populations in the CDC ALS registry, again likely due to regional differences, but also may reflect the same bias that is seen in referrals to clinical trials where patients from underrepresented populations are less likely to be referred to clinical trials.(13)

The response rate was just below the PCORI set target of $50 \%$, and did not appear to depend on the method of survey distribution. All but one site mailed out the questionnaire to their patients. One site used the EMR patient portal to communicate with their patients, and that site had a $28 \%$ response. The sites that had the better responses used a more personal approach, including mail and phone calls. We did have problems with consenting patients at one site, where survey response did not automatically get tied to the electronic consent. This reduced their response rate to $12 \%$ (University of Iowa). During the initial patient meetings, patients wanted the ability to answer surveys online. While indeed computer or tablets were the most frequent patientpreferred response modality, still less than $50 \%$ of the patients answered online.

The PADL-ALS had high correlation to in-person administered ALSFRS-R for the overlapping questions, similar to reports for self-administered versions of the ALSFRS-R,(14) and could distinguish between motor neuron disease subtypes based on functional burden. Of the added questions, the pseudobulbar affect question had the strongest correlation to the PADL-ALS questions 1-12, or the functional burden questions, and raises the possibility that by adding it we may increase the sensitivity of the PADL-ALS to disease progression. Pain likely represents an important question to follow in interventional studies, but it is disconnected from disease progression, and represents multi-factorial causes. The non-denominational question about faith does not strictly track with disease progression - for example it does not appear true that progression of motor neuron disease favors either gain or loss of faith. This question more likely would have utility at the individual respondent level, where a change in answer may trigger questions about the patient's well-being.

Limitations to the study include the Midwestern locations and the possible referral bias of the academic centers. ALS and motor neuron disorders more than other diseases tend to be followed in accredited multi-disciplinary clinics, making it more likely a patient will be seen at least once in these clinics. However, the nature of the disease to progress can limit respondents to those less severely affected or individuals with slower progression. The search criteria itself is limited by the physician properly coding the patient with a diagnosis in the EMR. Our search criteria limiting to the last two years might have excluded patients who either lived in a more rural location, so could not make 
frequent clinic visits, or patients who came to the academic center for diagnosis, but then were followed at local clinics.

Here we show the first effort to use the PCORIfunded GPC Research Network to use EMR-computable phenotypes to identify patients with ALS and other motor neuron disorders, then reach out to them with a survey. We show the feasibility of using a patient-informed revision of the ALSFRS-R, called the PADL-ALS, to track patient function, and query about future research directions. The responses to the survey set the stage for pragmatic studies exploring the patient-identified topics of interest, including the effects of diet or use of supplements on disease progression in ALS and other motor neuron disorders.

\section{Corresponding author:}

Richard J. Barohn, MD

Executive Vice Chancellor of Health Affairs,

University of Missouri

rbarohn@health.missouri.edu

\section{References}

1. Mehta P, Antao V, Kaye W, Sanchez M, Williamson D, Bryan L, et al. Prevalence of amyotrophic lateral sclerosis United States, 2010-2011. Morbidity and mortality weekly report Surveillance summaries. 2014;63 Suppl 7:1-14.

2. Statland JM, Barohn RJ, McVey AL, Katz JS, Dimachkie MM. Patterns of Weakness, Classification of Motor Neuron Disease, and Clinical Diagnosis of Sporadic Amyotrophic Lateral Sclerosis. Neurologic clinics. 2015;33(4):735-748.

3. The Amyotrophic Lateral Sclerosis Functional Rating Scale. Assessment of activities of daily living in patients with amyotrophic lateral sclerosis. The ALS CNTF treatment study (ACTS) phase I-II Study Group. Archives of neurology. 1996;53(2):141-147.

4. Cedarbaum JM, Stambler N, Malta E, Fuller C, Hilt D, Thurmond B, et al. The ALSFRS-R: a revised ALS functional rating scale that incorporates assessments of respiratory function. BDNF ALS Study Group (Phase III). Journal of the neurological sciences. 1999;169(1-2):1321.

5. Waitman LR, Aaronson LS, Nadkarni PM, Connolly DW, Campbell JR. The Greater Plains Collaborative: a PCORnet Clinical Research Data Network. Journal of the American Medical Informatics Association : JAMIA. 2014;21(4):637641.
6. Fleurence RL, Curtis LH, Califf RM, Platt R, Selby JV, Brown JS. Launching PCORnet, a national patientcentered clinical research network. J Am Med Inform Assoc. 2014 Jul-Aug;21(4):578-582.

7. Waitman LR, Warren JJ, Manos EL, Connolly DW. Expressing observations from electronic medical record flowsheets in an $\mathrm{i} 2 \mathrm{~b} 2$ based clinical data repository to support research and quality improvement. AMIA Annu Symp Proc. 2011;2011:1454-1463.

8. Murphy SN, Weber G, Mendis M, Gainer V, Chueh $\mathrm{HC}$, Churchill S, et al. Serving the enterprise and beyond with informatics for integrating biology and the bedside (i2b2). Journal of the American Medical Informatics Association : JAMIA. 2010;17(2):124-30.9. Harris PA, Taylor R, Thielke R, Payne J, Gonzalez N, Conde JG. Research electronic data capture (REDCap)--a metadatadriven methodology and workflow process for providing translational research informatics support. J Biomed Inform. 2009;42(2):377-381.

10. The Full Death Master File: SSA: Social Security Administration; 2017 [2019]. Available from: https://www. ssa.gov/dataexchange/request_dmf.html.

11. Graber ML, Byrne C, Johnston D. The impact of electronic health records on diagnosis. Diagnosis (Berl). 2017;4(4):211-223.

12. Registries for Evaluating Patient Outcomes. Third Edition ed. Richard E Gliklich MaNAD, MPH, PhD., editor. Rockville, MD: Agency for Healthcare Research and Quality (US); 2014.

13. Mainous AG, 3rd, Smith DW, Geesey ME, Tilley BC. Factors influencing physician referrals of patients to clinical trials. J Natl Med Assoc. 2008;100(11):1298-1303.

14. Montes J, Levy G, Albert S, Kaufmann P, Buchsbaum R, Gordon PH, et al. Development and evaluation of a self-administered version of the ALSFRS-R. Neurology. 2006;67(7):1294-1296. 
Appendix 1: PADL-ALS Survey.

\begin{tabular}{|c|c|}
\hline \multicolumn{2}{|c|}{ Today's Date: (day/month/year) $-I^{\prime}-I_{-}--$} \\
\hline $\begin{array}{l}\text { How did you complete this survey? } \\
\text { Please check one box }\end{array}$ & $\begin{array}{l}\square \text { In clinic using a paper form } \\
\square \text { At home using a paper form } \\
\square \text { In clinic using a computer or tablet } \\
\square \text { At home using a computer or tablet } \\
\square \text { At home by telephone (administered by clinic staff) }\end{array}$ \\
\hline $\begin{array}{l}\text { Who is completing the survey? } \\
\text { Please check one box }\end{array}$ & $\begin{array}{l}\square \text { Patient } \\
\square \text { Patient via Caregiver }\end{array}$ \\
\hline
\end{tabular}

\begin{tabular}{|c|c|c|}
\hline \multicolumn{2}{|c|}{ What diagnosis did your doctor tell you that you have? } & $\begin{array}{l}\square \text { ALS (Amyotrophic Lateral Sclerosis) } \\
\square \text { PLS (Primary Lateral Sclerosis) } \\
\square \text { PMA (Progressive Muscular Atrophy) } \\
\square \text { I do not know my diagnosis } \\
\square \text { Other (please enter): }\end{array}$ \\
\hline \multicolumn{2}{|c|}{$\begin{array}{l}\text { Would you be willing to be contacted about } \\
\text { opportunities to take part in our ALS Specialty Clinics } \\
\text { medical research? We are not keeping your name at } \\
\text { this time, we are just asking the number of possible } \\
\text { future participants. }\end{array}$} & $\begin{array}{l}\text { Yes! Please count me in! } \\
\square \text { No, I'm not able to at this time } \\
\square \text { Please ask me about a specific research project, } \\
\text { and then l'll decide }\end{array}$ \\
\hline \multicolumn{2}{|c|}{$\begin{array}{l}\text { When were you given your diagnosis, if known? (month } \\
\text { and year) }\end{array}$} & $--^{\prime}---$ \\
\hline \multicolumn{2}{|c|}{$\begin{array}{l}\text { When did your symptoms / weakness start? (month } \\
\text { and year; we understand that this might be a "best } \\
\text { guess" or estimate) }\end{array}$} & $--^{l}----$ \\
\hline \multicolumn{3}{|c|}{ In what region(s) of your body did the first symptoms of ALS begin? (please be as specific as possible) } \\
\hline \multirow{6}{*}{\begin{tabular}{|c|} 
Area \\
Hand \\
Foot \\
Arm \\
Leg \\
Swallowing \\
\end{tabular}} & Right Side & Left Side \\
\hline & $\square$ & $\square$ \\
\hline & $\square$ & $\square$ \\
\hline & $\square$ & $\square$ \\
\hline & $\square$ & $\square$ \\
\hline & $\square$ & \\
\hline \multicolumn{3}{|l|}{ Speech } \\
\hline \multicolumn{3}{|c|}{ Breathing $\square$} \\
\hline \multicolumn{2}{|c|}{ Other? (please write in): } & \\
\hline
\end{tabular}

Page 1 of 5 ALS Survey; 2014 Copyright; University of Kansas; All Rights Reserved 


\section{DIRECTIONS for the following questions:}

Please think about how you are doing on an average day over the past month or so (and this includes your routine use of therapies, devices, medications, etc.) when answering these questions. Total score at end.

\section{Speech}

$\square 4$ Normal speech processes

$\square 3$ Detectable speech with disturbances

$\square 2$ Intelligible with repeating

$\square 1$ Speech combined with non-vocal communication

$\square 0$ Loss of useful speech

\section{Salivation}

$\square 4$ Normal

$\square 3$ Slight, but definite excess of saliva in mouth; may have nighttime drooling

$\square 2$ Moderately excessive saliva; may have minimal drooling

$\square 1$ Marked excess of saliva with some drooling

$\square 0$ Marked drooling; requires constant tissue or handkerchief

\section{Swallowing}

$\square 4$ Normal eating habits

$\square 3$ Early eating problems - occasional choking

$\square 2$ Dietary consistency changes

$\square 1$ Needs supplemental tube feeding

$\square 0$ Feeding tube only

\section{Handwriting (with the hand you normally write with)}

$\square 4$ Normal

$\square 3$ Slow or sloppy; all words are legible

$\square 2$ Not all words are legible

$\square 1$ Able to grip pen but unable to write

$\square 0$ Unable to grip pen

5. Please answer question 5a if you do not have a feeding tube or if you require the use of a feeding tube for $50 \%$ or LESS of your nutritional needs.

\section{5a. Cutting food and handling utensils}

$\square 4$ Normal

$\square 3$ Somewhat slow and clumsy, but no help needed

$\square 2$ Can cut most foods, although clumsy and slow; some help needed

$\square 1$ Food must be cut by someone, but can still feed slowly

$\square 0$ Needs to be fed

Page 2 of 5 ALS Survey; 2014 Copyright; University of Kansas; All Rights Reserved 
Appendix 1: PADL-ALS Survey.

Please answer question $5 b$ if you always use a feeding tube OR if you have a feeding tube and use it MORE than $50 \%$ of the time for your nutritional needs.

5b. Cutting food and/or handling feeding tube closures, cans or utensils

$\square 4$ Normal

$\square 3$ Clumsy, but able to perform all manipulations independently

$\square 2$ Some help needed with closures and fasteners

$\square 1$ Provides minimal assistance to caregivers

$\square 0$ Unable to perform any aspect of task

\section{Dressing and hygiene}

$\square 4$ Normal function

$\square 3$ Independent and complete self-care with effort or decreased efficiency

$\square 2$ Intermittent assistance or substitute methods (can include zipper pulls, button fasteners, sitting instead of standing)

$\square 1$ Need attendant for self-care

$\square 0$ Total dependence

\section{Turning in bed and adjusting sheets}

$\square 4$ Normal

$\square 3$ Somewhat slow and clumsy, but no help needed

$\square 2$ Can turn alone or adjust sheets, but with great difficulty

$\square 1$ Can initiate, but not turn or adjust sheets alone

$\square 0$ Helpless

\section{Walking}

$\square 4$ Normal

$\square 3$ Early ambulation difficulties

$\square 2$ Walks with assistance (includes holding on to someone's arm)

$\square 1$ Non-ambulatory functional movement only

$\square 0$ No purposeful leg movement

\section{Climbing stairs \\ $\square 4$ Normal \\ $\square 3$ Slow \\ $\square 2$ Mild unsteadiness or fatigue \\ $\square 1$ Needs assistance \\ $\square 0$ Cannot do}

Page 3 of 5 ALS Survey; 2014 Copyright; University of Kansas; All Rights Reserved 
Appendix 1: PADL-ALS Survey.
10. Shortness of breath (Dyspnea)
$\square 4$ None
$\square 3$ Occurs when walking
$\square 2$ Occurs with one or more of the following: eating, bathing, dressing
$\square 1$ Occurs at rest, difficulty breathing when either sitting or lying
$\square 0$ Significant difficulty, considering using mechanical respiratory support

\section{Trouble breathing while lying down (Orthopnea)}

$\square 4$ None

$\square 3$ Some difficulty sleeping at night due to shortness of breath; does not routinely use extra pillow(s)

$\square 2$ Need extra pillow(s) in order to sleep (at least one pillow more than usual)

$\square 1$ Can only sleep sitting up

$\square 0$ Unable to sleep

12. Breathing Assistance/Respiratory Insufficiency (Note: A BiPAP is a machine that changes the pressure as per the breathing pattern; a CPAP is a machine that delivers air pressure at a single level. Both machines make it easier to breathe.)

$\square 4$ None

$\square 3$ Intermittent use of BiPAP or CPAP

$\square 2$ Continuous use of BiPAP or CPAP during the night

$\square 1$ Continuous use of BiPAP or CPAP during the night and day

$\square 0$ Invasive mechanical ventilation by intubation or tracheostomy or noninvasive mechanical ventilation

\section{Pain}

$\square 4$ No pain

$\square 3$ Some pain, but does not limit my activities

$\square 2$ Pain that minimally limits my activities

$\square 1$ Pain that moderately limits my activities

$\square 0$ Severe pain that limits what I can do

\section{Crying or laughing uncontrollably}

$\square 4$ No problems

$\square 3$ Sometimes, but it doesn't interfere with my daily activities

$\square 2$ Yes, and this causes some minor limits on my activities outside of my home

$\square 1$ Yes, and this moderately limits my activities outside of my home

$\square 0$ Yes and I am unable to control it and it severely limits my activities outside of my home

Page 4 of 5 ALS Survey; 2014 Copyright; University of Kansas; All Rights Reserved 
Appendix 1: PADL-ALS Survey.

15. For some people, their religious or spiritual beliefs act as a source of comfort and strength in dealing with life's ups and downs; is this true for you?

$\square 4$ This is very true for me

$\square 3$ This is usually true for me

$\square 2$ It depends - sometimes this is true and sometimes not

$\square 1$ This is usually not true for me

$\square 0$ This is not at all true for me

16. In addition to brand new experimental treatments for ALS, it is also important that we study how to best use currently available treatments. Which of the following clinical research questions would you be interested in knowing the answer to? (check all that apply)

Is there a benefit to combining drug therapies in ALS? (For example, testing if combining two currently available drugs with riluzole benefits patients)

Are there vitamin combinations/herbal supplements which can slow down ALS?

Does starting BiPAP earlier provide any benefit in ALS?

Do special diets have any role in treatment of ALS?

What is the best way to treat throat spasms that lead to choking or coughing?

$\square$ Do you have an idea for research that you would like to share? Please write in below

17. Is there something you'd like to share that we have not asked about? Please use this space to tell us! Please do not enter any information in this area that we would be able to identify you. This includes name, date of birth, location.

THANK YOU VERY MUCH FOR COMPLETING THE SURVEY!

Total Score for Items 1- 15 above:

Page 5 of 5 ALS Survey; 2014 Copyright; University of Kansas; All Rights Reserved 
Appendix 2: Co-investigators, collaborators and co-authors*

\begin{tabular}{|c|c|c|c|}
\hline Name & Location & Role & Contribution \\
\hline Tiffany Robinson & $\begin{array}{l}\text { University of Kansas Medical Center, } \\
\text { Kansas }\end{array}$ & $\begin{array}{l}\text { Regulatory } \\
\text { Project Manager }\end{array}$ & $\begin{array}{l}\text { IRB submissions, gather regulatory } \\
\text { documents }\end{array}$ \\
\hline Tamara McMahon & $\begin{array}{l}\text { University of Kansas Medical Center, } \\
\text { Kansas }\end{array}$ & Honest Broker & Designed the database \\
\hline Carlayne Jackson, MD & $\begin{array}{l}\text { University of Texas Health Science } \\
\text { Center, San Antonio }\end{array}$ & Site Investigator & Role in the acquisition of data \\
\hline Pam Kittrell, RN & $\begin{array}{l}\text { University of Texas Health Science } \\
\text { Center, San Antonio }\end{array}$ & $\begin{array}{l}\text { Study } \\
\text { Coordinator }\end{array}$ & Role in the acquisition of data \\
\hline Alfredo Tirado-Ramos, PhD & $\begin{array}{l}\text { University of Texas Health Science } \\
\text { Center, San Antonio }\end{array}$ & GPC PI & $\begin{array}{l}\text { Supported this study through their } \\
\text { GPC }\end{array}$ \\
\hline Angela Bos & $\begin{array}{l}\text { University of Texas Health Science } \\
\text { Center, San Antonio }\end{array}$ & Honest Broker & Ran queries to recruit patients \\
\hline Jaya Trivedi, MD & $\begin{array}{l}\text { University of Texas Southwestern } \\
\text { Medical Center, Dallas }\end{array}$ & Site Investigator & Role in the acquisition of data \\
\hline Sharon Nations, MD & $\begin{array}{l}\text { University of Texas Southwestern } \\
\text { Medical Center, Dallas }\end{array}$ & Co-Investigator & Role in the acquisition of data \\
\hline $\begin{array}{l}\text { Lindsay Cowell, PhD - GPC } \\
\text { PI }\end{array}$ & $\begin{array}{l}\text { University of Texas Southwestern } \\
\text { Medical Center, Dallas }\end{array}$ & GPC PI & $\begin{array}{l}\text { Supported this study through their } \\
\text { GPC }\end{array}$ \\
\hline J. Americo Fernandes, MD & $\begin{array}{l}\text { University of Nebraska Medical } \\
\text { Center, Omaha }\end{array}$ & Site Investigator & Role in the acquisition of data \\
\hline Jim McClay, MD & $\begin{array}{l}\text { University of Nebraska Medical } \\
\text { Center, Omaha }\end{array}$ & $\begin{array}{l}\text { GPC PI/Honest } \\
\text { Broker }\end{array}$ & $\begin{array}{l}\text { Supported this study through their } \\
\text { GPC; Ran queries to recruit patients }\end{array}$ \\
\hline Deborah Heimes & $\begin{array}{l}\text { University of Nebraska Medical } \\
\text { Center, Omaha }\end{array}$ & $\begin{array}{l}\text { Study } \\
\text { Coordinator }\end{array}$ & Role in acquisition of data \\
\hline Lisa Houdesheldt & $\begin{array}{l}\text { University of Nebraska Medical } \\
\text { Center, Omaha }\end{array}$ & $\begin{array}{l}\text { Study } \\
\text { Coordinator }\end{array}$ & Role in acquisition of data \\
\hline Andrea Swenson, MD & $\begin{array}{l}\text { University of Iowa Hospitals \& Clinics, } \\
\text { Iowa City }\end{array}$ & Site Investigator & Role in acquisition of data \\
\hline Gary Rosenthal, MD & $\begin{array}{l}\text { University of Iowa Hospitals \& Clinics, } \\
\text { Iowa City }\end{array}$ & GPC PI & $\begin{array}{l}\text { Supported this study through their } \\
\text { GPC }\end{array}$ \\
\hline Jeri Sieren & $\begin{array}{l}\text { University of Iowa Hospitals \& Clinics, } \\
\text { Iowa City }\end{array}$ & $\begin{array}{l}\text { Study } \\
\text { Coordinator }\end{array}$ & Role in acquisition of data \\
\hline Prakash Nadkarni & $\begin{array}{l}\text { University of Iowa Hospitals \& Clinics, } \\
\text { Iowa City }\end{array}$ & Honest Broker & Ran queries to recruit patients \\
\hline David Walk, MD & University of Minnesota, Minneapolis & Site Investigator & Role in acquisition of data \\
\hline Connie Delaney, PhD & University of Minnesota, Minneapolis & GPC PI & $\begin{array}{l}\text { Supported this study through their } \\
\text { GPC }\end{array}$ \\
\hline Michelle Coady & University of Minnesota, Minneapolis & $\begin{array}{l}\text { GPC Study } \\
\text { Coordinator }\end{array}$ & Supported the site coordinator \\
\hline Deborah Schiltz & University of Minnesota, Minneapolis & $\begin{array}{l}\text { Study } \\
\text { Coordinator }\end{array}$ & Role in acquisition of data \\
\hline Supreet Kathpalia, MS & University of Minnesota, Minneapolis & Honest Broker & Ran queries to recruit patients \\
\hline Andrew Waclawik, MD & University of Wisconsin, Madison & Site Investigator & Role in acquisition of data \\
\hline Marc Drezner, MD & University of Wisconsin, Madison & GPC PI & $\begin{array}{l}\text { Supported this study through their } \\
\text { GPC }\end{array}$ \\
\hline Andrea Maser, MS & University of Wisconsin, Madison & $\begin{array}{l}\text { Study } \\
\text { Coordinator }\end{array}$ & Role in acquisition of data \\
\hline $\begin{array}{l}\text { Eneida Mendonca, MD, } \\
\mathrm{PhD}\end{array}$ & University of Wisconsin, Madison & $\begin{array}{l}\text { Primary Honest } \\
\text { Broker }\end{array}$ & Ran queries to recruit patients \\
\hline Tom Mish, BCG/SMPH & University of Wisconsin, Madison & $\begin{array}{l}\text { Secondary } \\
\text { Honest Broker }\end{array}$ & Ran queries to recruit patients \\
\hline Paul Barkhaus, MD & $\begin{array}{l}\text { Medical College of Wisconsin, } \\
\text { Milwaukee }\end{array}$ & Site Investigator & Role in acquisition of data \\
\hline Bradley Taylor, PhD & $\begin{array}{l}\text { Medical College of Wisconsin, } \\
\text { Milwaukee }\end{array}$ & GPC PI & $\begin{array}{l}\text { Supported this study through their } \\
\text { GPC }\end{array}$ \\
\hline Jo Berghotle & $\begin{array}{l}\text { Medical College of Wisconsin, } \\
\text { Milwaukee }\end{array}$ & $\begin{array}{l}\text { Study } \\
\text { Coordinator }\end{array}$ & Role in acquisition of data \\
\hline Lynn Wheeler & $\begin{array}{l}\text { Medical College of Wisconsin, } \\
\text { Milwaukee }\end{array}$ & $\begin{array}{l}\text { Study } \\
\text { Coordinator }\end{array}$ & Role in acquisition of data \\
\hline
\end{tabular}


Appendix 1: Co-investigators, collaborators, and co-authors*

\begin{tabular}{|c|c|c|c|}
\hline Name & Location & Role & Contribution \\
\hline Sabrina Uppal & $\begin{array}{l}\text { Medical College of Wisconsin, } \\
\text { Milwaukee }\end{array}$ & $\begin{array}{l}\text { Study } \\
\text { Coordinator }\end{array}$ & Role in acquisition of data \\
\hline Glenn Bushee & $\begin{array}{l}\text { Medical College of Wisconsin, } \\
\text { Milwaukee }\end{array}$ & Honest Broker & Ran queries to recruit patients \\
\hline Kathy Williams & $\begin{array}{l}\text { Medical College of Wisconsin, } \\
\text { Milwaukee }\end{array}$ & Honest Broker & Ran queries to recruit patients \\
\hline Jamie Boero, MD & Marshfield Clinic, Marshfield & Site Investigator & Role in acquisition of data \\
\hline Robert Greenlee, MD & Marshfield Clinic, Marshfield & GPC PI & $\begin{array}{l}\text { Supported this study through their } \\
\text { GPC }\end{array}$ \\
\hline Deb Multerer & Marshfield Clinic, Marshfield & $\begin{array}{l}\text { Study } \\
\text { Coordinator }\end{array}$ & Role in acquisition of data \\
\hline Laurel Verhagen & Marshfield Clinic, Marshfield & Honest Broker & Ran queries to recruit patients \\
\hline
\end{tabular}

